\title{
Promoted Peer Review in EFL Writing: Development in Students' Perceptions and Feedback
}

\author{
Rashed Nasir Altamimi ${ }^{1}$ \\ ${ }^{1}$ College of Languages and Translation, King Saud University, Riyadh, Saudi Arabia \\ Correspondence: Rashed Nasir Altamimi, College of Languages and Translation, King Saud University, zip code \\ 11472, P. O. Box 7805, Riyadh 11564-11564, Saudi Arabia. E-mail: raltamimi2021@gmail.com
}

Received: June 27, $2020 \quad$ Accepted: September 23, $2020 \quad$ Online Published: October 28, 2020

doi:10.5539/ijel.v10n6p381 URL: https://doi.org/10.5539/ijel.v10n6p381

\begin{abstract}
While many studies have examined the impact of peer review on EFL students' perceptions of peer review and acceptance and incorporation of feedback in their writing with the help of training or guidance and guide (check list), using a combination of these techniques plus multiplicity of review sessions, as a promotion, has been underexplored. This study aims to investigate the usefulness of training, guidance, and multiplicity of peer review sessions in changing students' negative perceptions of peer review and increasing their acceptance and incorporation of feedback in EFL writing. Two training workshops and checklists were used to help students do the review, which was accomplished in five multiple sessions. Thirty-four students voluntarily participated in this study, which employed a five-item pre-/post methodology — the online survey and students' written drafts as data collection instruments. To analyze the data, independent samples t-tests were used for the five-item survey, percentage of each peer session's comments (i.e., comments made/comments incorporated) was calculated to assess peers' acceptance of their partners' feedback, and a repeated-measures ANOVA was conducted to determine whether participants incorporated more feedback over time. The results showed that, first, the participants revealed positive perceptions of the effectiveness of peer review. Second, the students highly accepted their peers' feedback. Finally, the students incorporated a significantly higher quantity of reviewers' feedback into second drafts at the end of every session, starting from the second session. The pedagogical implications of these findings are discussed.
\end{abstract}

Keywords: perceptions, promoted peer review, feedback, EFL writing

\section{Introduction}

\subsection{Statement of the Problem}

One of the tasks that can benefit second language (L2) learners in the writing process is engaging them in peer response sessions. Peer review (i.e., peer response, peer feedback) is not limited to evaluating writing tasks; it entails having the students participate in many types of written and oral communication to provide comments on each other's writings. Peer review is the technique of using feedback from sources other than the teacher.

During the past four decades, feedback has been increasingly incorporated into English as a second/foreign language (ESL/EFL) writing classrooms (Nguyen, 2019). Many researchers have acknowledged that peer review plays a pivotal role in enhancing students' writing skills and learning achievement (Homayounzadeh et al., 2016; Mirzaei \& Eslami, 2015; Naser \& Behzad, 2017). Peer review activity has been seen as an essential component of L2 writing (Austria, 2017; Baker, 2016; Brusa \& Harutyunyan, 2019; Khalil, 2018; Min, 2016; Nguyen, 2016). Peer review allows learners to develop effective strategies, support critical thinking skills, and develop socially and intellectually through working collaboratively. Additionally, it helps them practice to become more independent learners (Kuyyogsuy, 2019). Students' evolution through peer feedback has not only been proven to have positive effects on specific issues of novice students' writing mistakes, but there have also been proven increases in the overall holistic scores of students. Therefore, peer review deserves exploration and investigation.

Many studies about students' peer review have not investigated the effect of peer review-with an emphasis on training students, using specific guidance and guide while reviewing, and engaging students in multiple sessions - on students' perceptions of peer review and their acceptance and incorporation of feedback in L2 writing classes. For example, Hojeij and Baroudi (2018), Bui and Kong (2019), and Pham et al. (2020) examined 
the effect of training on undergraduate EFL students' perceptions of peer review and their writing development. Other researchers have studied peer feedback from a different perspective, by examining the effects of the types and traits of feedback on EFL students' writing development (Leijen, 2017; Saeed et al., 2018). A third group of studies did not use any of the techniques mentioned above (training and/or guidance) or types and traits of feedback in peer review (Harutyunyan \& Poveda, 2018; Zhu \& Carless, 2018). There is a gap in the literature for studies that combine the two techniques (training and guidance with the help of guide) plus the multiplicity of peer sessions to see how they affect EFL students' perceptions of peer review and their acceptance and incorporation of feedback in EFL writing classes.

This study is an attempt to address the issue of combining training, guidance, and multiplicity of peer sessions and their influence on students' perceptions, acceptance, and incorporation of feedback in EFL writing.

The main aim of this study is to find out the effect of promoted peer review on undergraduate EFL students' perceptions of peer review and to see to what extent the students accept and incorporate peer feedback in writing classes after participating in promoted peer review.

\subsection{Literature Review}

\subsubsection{Students' Perceptions of the Efficacy of Peer Feedback in L2 Writing}

This section focuses on how students perceive the usefulness of peer feedback. The studies cited here have shown varied results, and hence, both positive and negative findings have been presented. Some studies have found that ESL students truly appreciate peer feedback, believing that it is beneficial and enhances their writing abilities (Harutyunyan \& Poveda, 2018; Yastibas \& Yastibas, 2015; Yu \& Lee, 2016). For instance, Zhu and Carless (2018) carried out a study that aimed to unpack the respective perceptions of the provider and the receiver of peer feedback about the benefits and challenges of dialogue about academic writing. The researchers found that the provider of written comments obtains feedback on their feedback, and the receiver has the opportunity to clarify or negotiate meaning with the feedback provider. In the same way, Harutyunyan and Poveda (2018) presented an analysis of the perceptions of 44 students at one of the largest universities in Ecuador, who had just undertaken a course in academic writing that used peer revision as the main tool for improving final essay compositions. The researchers showed that participants of the groups who followed a peer revision approach believed that they benefited from this method. Likewise, Yastibas and Yastibas (2015), in their study that investigated the effects of peer feedback on Turkish EFL students' writing anxiety and perceptions toward the feedback, found that the students believed using peer feedback in writing classes decreased their writing anxiety, increased their confidence, and improved their writing by collaborating with and learning from each other. Not surprisingly, a recent study conducted by Park (2018) that attempted to explore whether teacher and peer feedback can be effectively implemented in an EFL writing classroom at the tertiary level revealed that most students appreciated peer feedback because they could learn new perspectives and expressions. Students also felt less obliged to accept all of their peers' comments, compared to teachers' feedback, leading them to critically evaluate their usefulness.

Other experts have maintained that, with proper guidance and training, ESL students could offer specific, focused, and more meaning-based responses even though they are not writing in their first language, resulting in students finding their peers' feedback useful and thus improving their attitudes toward it (Bui \& Kong, 2019; Cahyono \& Amrina, 2016; Hojeij \& Baroudi, 2018). For example, Cahyono and Amrina (2016) investigated the effectiveness of peer feedback and self-correction based on guideline sheets on the writing ability of Indonesian EFL students. They found that the students given peer feedback based on a guideline sheet had better ability in writing essays than those who were not given peer feedback; the students conducting self-correction based on a guideline sheet had better ability in writing essays than those who did not conduct self-correction, and both peer feedback based on a guideline sheet and self-correction based on a guideline sheet significantly improved the ability in writing essays of the students in the two experimental classes. A subsequent study by Hojeij and Baroudi (2018) examined the effect of peer reviewing training on the motivation and engagement levels toward self- and peer-reviewing of undergraduate students who were Arabic native speakers at a foundation intermediate English class. Investigating students' perceptions and attitudes, Hojeij and Baroudi (2018) found that combining peer editing training with face-to-face and mobile learning tools had a positive impact on EFL students' revisions and overall writing. Students were able to generate specific feedback on global as well as formal issues. Moreover, the researchers found that peer review promoted students' proficiency, and more significantly, most students appreciated their peers' feedback and considered their comments to be just as effective as the teacher's. Using a different type of training, Bui and Kong (2019) explored the role of metacognitive training in changing L2 learners' negative perceptions of peer review. They showed that 
metacognitive training in peer review helped change the perceptions of L2 learners and increased their level of engagement and collaboration during the peer review tasks.

In contrast, other studies have found teacher feedback to be much more beneficial, as students were more likely to use the comments of their teacher than those of their peers when revising their papers (Ruegg, 2018; Suryani et al., 2019). For example, Suryani et al. (2019) argued that some students valued the teacher's feedback more highly than peer feedback. These students believed that it was more possible to achieve grammatical accuracy through teacher feedback than through peer feedback because they thought that their peers had inadequate grammar knowledge.

Other researchers who doubt the benefits and effectiveness of peer feedback have claimed that it is counterproductive for students who come from culturally non-Western backgrounds, as they are used to admiring and respecting ranked culture rather than a group consensus among peers (Fithriani, 2018). According to Fithriani (2018), students found teacher feedback more valuable than peer feedback, which indicated the influence of a hierarchical culture. However, they were not concerned about practicing face-saving strategies to maintain group harmony and cohesion, which is quite common in other Asian societies. Similarly, Domysheva and Kopylova (2019) reported that peer review is not a very common practice in EFL writing classes in Russia, although it is viewed mostly in a positive way by both faculty and students. In this study, Domysheva and Kopylova also showed that limitations on using peer review are caused by such inherent cultural characteristics as a high degree of collectivism and high-power distance. These cultural values, believed to be typical of Russians, are manifested in educational settings, yet there is no unanimity among faculty or students about the extent of this manifestation. Moreover, there is a considerable discrepancy between teachers' and students' views on whether learning should be a student- or teacher-centered.

The vastly different results of the studies mentioned here suggest that outside variables (training, teacher's guidance, culture, etc.) play a large role when it comes to students' attitudes toward peer feedback. This can limit the effectiveness of the peer review process, and as a result, students do not perceive its benefits. Taking these factors into consideration, ESL/EFL teachers can help students develop more positive perceptions of the effectiveness of peer feedback in their writing.

\subsubsection{Promoters and Benefits of Acceptance and Incorporation of Peer Feedback in EFL Students' Writing}

This section focuses on promoters and benefits of peer feedback in EFL students' writing. The studies cited here support the potential use of acceptance and incorporation of peer feedback in improving EFL students' writing skills and developing their extra-linguistic knowledge (Kuyyogsuy, 2019; Lei, 2017; Leijen, 2017; Pham et al., 2020; Saeed et al., 2018). However, the studies differ in the ways the researchers approach them. The following part reviews some of the studies that have showed the promoters and benefits of acceptance and incorporation of peer feedback for students in EFL writing classes.

Focusing on written feedback, Lei (2017), who investigated the incorporation and effectiveness of student-written feedback and students' attitudes toward peer feedback in writing classes, showed that most student-written feedback and suggestions are generally accepted and incorporated in EFL students' writing revisions. According to Lei, "Peer feedback provides them with more chances to discuss with their peers and understand their peers' suggestions on the composition improvement" (p. 151).

Similar to Lei (2017), Pham et al. (2020) examined the quality of trained written peer feedback and the effects of such feedback on students' revisions. However, Pham et al. added quality training to the written feedback. In other words, what was examined was the quality of trained written feedback and the effects of trained written feedback on students' revisions. According to Pham et al. (2020), "Most of the peer comments were revision-oriented and the quantity of accurate comments was remarkably higher than the quantity of mis-corrections" (p. 45). Also, peer comments triggered most of the revisions in the second drafts and significantly improved the writing quality among both low- and high-level writers.

Likewise, and in an attempt to find empirical evidence of learners' incorporation of peer interactional feedback in their text revision, Saeed et al. (2018) reviewed previous studies on learners' interactional feedback exchanges in face-to-face peer review (FFPR) and computer-assisted peer review (CAPR) of ESL/EFL writing. One study reported that the percentage of learners' integration of peer feedback into their writing was affected by the mode of peer review (Song \& Usaha, 2009). Song and Usaha reported that the higher rate of feedback comments' incorporation into learners' text revision was found in CAPR mode. This implies that the comments are written and learners have time to read and understand them well, and as a result integrate their peers' suggestions into their text revisions, as opposed to FFPR mode, where feedback comments are oral. 
From a different perspective, Leijen (2017) investigated how revisions made in subsequent drafts, using a web-based peer review system, are influenced by the types and traits of feedback. The researcher suggested that particular types of feedback, alteration and recurring, are important predictors for revision.

Considering patterns of interactions and students' viewpoints toward incorporating peer feedback in an L2 writing class, Kuyyogsuy (2019) showed that the identified patterns of the collaborative and expert/novice instances improved students' writing performance. Kuyyogsuy (2019) discovered that "Specifically, students perceived the writing process, developed affective strategies, reinforced their critical thinking ability, and enhanced their social interaction skills. Besides, it encouraged them to become more effectively autonomous learners" (p. 191).

To summarize, the literature about the benefits of acceptance and incorporation of peer feedback in EFL writing classes has found that peer feedback plays a crucial role in developing EFL students' writing skills and extralinguistic skills. Moreover, the most useful kind of peer feedback is written feedback, whether it is used alone or with support, such as training or guidance and guide, because students have time to read and understand the feedback well and consequently integrate their peers' suggestions into their text revisions. Also, incorporating peer feedback in L2 writing classes is influenced by types and traits of feedback as well as the patterns of interactions between students.

\subsection{Research Questions}

The following research questions were addressed in this study:

1) How do students perceive the effectiveness of peer review on their L2 writing after participating in promoted peer review?

2) To what extent do students accept and incorporate their peers' feedback in L2 writing after participating in promoted peer review?

\section{Materials and Methods}

\subsection{Research Design}

For this study, I utilized a quantitative method of data collection and analysis to address the research questions thoroughly, gain a better understanding of the research situation, and - most importantly — obtain more reliable findings of students' perceptions of peer review and acceptance and incorporation of peer comments in EFL writing classes.

\subsection{Population of the Study}

The target population of this study was male Saudi undergraduate students majoring in English at the College of Languages and Translation at King Saud University. This college has different departments, such as the English Language Department, the French Language Department, and the Languages Unit. The students study at the English Language Department. At the time of the study they had completed an intensive preparatory-year program (two academic semesters).

\subsection{Sampling Method}

Through purposive sampling, 42 students were enrolled, but, due to registration issues, this number decreased to 34. I carried out certain procedures to ensure the consideration of all the relevant ethical issues. First, I followed the University of Memphis Institutional Review Board (IRB) regulations and the committee chair's instructions by obtaining written permission from the university at which the project was carried out. IRB approval was obtained prior to the start of the study. Participants were also given a detailed description of the nature of the study and their tasks during the study. They were provided a thorough explanation of the study, including its objectives, procedures of data collection, participants' roles, rights, protection of identity, and the potential benefits and ethical challenges of participating in the project. Participants received informed consent forms and were given sufficient time to decide whether they wanted to participate. All information obtained from the participants was kept secure and confidential. The students' records and data provided were maintained in a personal locker and used only for the study. All the participants had the option to reveal their identities or use pseudonyms.

\subsection{Sample of the Study}

The participants of this study consisted of 34 male Saudi university students majoring in English at the College of Languages and Translation (COL\&T) at King Saud University, a major university in Saudi Arabia. The COL\&T is one of many colleges at that university and has different departments, as described above. The 
participants came from the English Language Department. Students must complete an intensive preparatory-year program (two academic semesters) to join the COL\&T. The English program in that academic year is designed to develop skills in English through speaking, listening, reading, and writing. Students who want to be admitted to the English Department must meet the following requirements, as determined by the COL\&T council:

1) Earn a $3.75+$ (out of 5) GPA during the preparatory-year program.

2) Achieve a minimum grade of $\mathrm{B}+$ in the English component.

Accordingly, students are expected to hold a minimum level of intermediate English proficiency once they finish the preparatory-year program.

Students who join the English program at the COL\&T must complete three writing courses in the first three semesters: Writing I, Writing II, and Essay Writing and Summarization. Each writing course is a prerequisite for the next. For students to enroll in the subsequent course, they must earn at least $60 \%$ of the possible overall score. The writing textbook series assigned for this program includes the volumes Interactions II, Mosaic I, and Mosaic II by Cheryl Pavlik and Margaret Segal.

The 34 participants were in their second year of the English program and enrolled in the Writing II and Writing III courses, each of which is taught for $150 \mathrm{~min}$ per week for the whole semester. These two courses are prerequisites for ENG 323, Essay Writing and Summarization, in which this experiment was conducted. This course is also taught for 150 min per week, and students cannot waive this course. During the course, students learn how to write three-to-five-paragraph essays, mostly argumentative ones. The five diverse writing prompt topics were about friendship, studying English, the Internet, violent crimes, and alternative energy. In terms of their overall language proficiency, most students were at level five and had completed Writing II and Writing III.

For this research, I adopted what is called the peer-tutoring method, where a teacher selects learners who perform well to tutor others who are having difficulties with the lesson. This method is more applicable in colleges, universities, and other higher-learning institutions.

\subsubsection{Training the Participants: Guidelines, Sample Essay, Suggestions, and Timeline}

Training on peer sessions in writing classes has been supported by several researchers (e.g., Kim, 2015; Memari Hanjani \& Li, 2015). In a similar study by Memari Hanjani (2019), learners were required to develop a 150-word paragraph in two drafts (pre- and post-collective scaffolding). Using similar strategies suggested by these studies, I attempted to develop appropriate training techniques to enable students to participate in the peer-review process effectively. The training process involved four hrs of class time, during which the students were introduced to the peer review concept and the checklist, practiced it themselves, and participated in a follow-up teacherstudent classroom discussion. To ensure that students received the necessary preparation for the upcoming task, I kept in constant contact with the teacher to identify each step of the training process vividly.

To begin the training, the teacher introduced the peer review concept and its significance. The students were provided with detailed guidelines to help them identify the writing problems they might find in their partners' work. Students were introduced to a checklist to help them distinguish the different types of mistakes in each other's writing - namely, global (i.e., organization, development, and cohesion) and local (i.e., grammar, vocabulary, and mechanics) aspects of writing. The teacher presented a sample essay with different writing problems and, following those guidelines, engaged the students in reviewing the essay to ensure that they understood the task. In this way, students became more familiar with the rubrics used to identify the writing problems related to both the form and content. Furthermore, many strategies for giving clear and beneficial feedback were discussed and brought to the students' attention to use the checklist effectively. These suggestions were recommended by previous studies (e.g., Kong \& Bui, 2019) on how students negotiate their comments by asking writers for clarification, explaining the mistakes, and making suggestions. The following recommended suggestions were used in this study to train students to be better reviewers:

- Be friendly and introduce yourself.

- Stay positive and show interest.

- Ask probing questions when needed to clarify the writer's intention or meaning to help you provide accurate comments. Examples include "Do you mean that ...?", “Are you saying ...?", "What do you mean by ...?", or "I do not get this ...?" (to prompt the writer to explain or revise his ideas).

- Balance between giving praise and criticism.

- Give suggestions for improvement; point out the areas that the writer may need to revise and improve on and give specific suggestions to enrich the content. Most importantly, offer suggestions politely (e.g., "I think you 
should give more examples ..." and "In my opinion, you need to add more supporting ideas like ...").

The training lasted for 2 weeks as the teacher repeated the instruction more than once, especially for absent students. Students' implementation of the peer commenting steps was closely observed. Whenever students had issues that would affect their understanding of providing peer response, the instructor addressed those concerns as soon as possible. Students identified many concerns, particularly in the first peer session (as expected), such as fully understanding some items listed on the checklist, providing inappropriate comments or ideas, or giving suggestions. These concerns were discussed and handled by the teacher, and most students had a better understanding of their tasks in the second peer session.

\subsection{Data Collection Instruments}

\subsubsection{Survey}

I developed a pre-/post-survey instrument (five items) to gather the appropriate answers for the first question (Appendix A). Using Qualtrics (an online survey website), I administered and distributed the survey, which included closed-ended questions on a 5-point Likert scale in a multiple-choice format: Strongly Disagree, Disagree, Don't Know, Agree, and Strongly Agree.

The pre-survey included a section on students' demographic information and background in both English proficiency and peer review activities. In addition, five items were incorporated to obtain students' overall perceptions of the effectiveness of peer review sessions on their writing. These items were also included in the post-survey to compare the answers, thereby enabling me to observe and explore any difference in the perceptions.

\subsubsection{Students' Written Texts and Checklist}

Students' written texts. For this study, the students' writings - both the first drafts written before the peer sessions and the final drafts written after they reviewed each other's papers-were collected. These texts helped illustrate the extent to which students accepted their classmates' comments and incorporated them into their final drafts. Their comments on the first draft were identified and quantified to be compared with the total number of changes made according to their classmates' feedback on their writings.

Checklist. This study employed a checklist with items covering local and global issues in writing. After thoroughly examining several checklists, I used the checklist (Appendix B) designed by Aldossary (2016) for this research because it was developed and employed in the same context (i.e., the COL\&T) and for students with a similar English proficiency level as participants in this study. The students were supposed to benefit from the checklists while evaluating their classmates' writing before engaging in a peer session to discuss their feedback.

\subsection{Data Collection Procedures}

The students were informed of the study and were provided with a detailed description of their tasks. Before they started, students were asked to complete the pre-survey. During the first 2 weeks, the students were provided with two training workshops on peer sessions. Starting in the 3rd week, participants began writing their responses to the writing prompts assigned. Every 2 weeks, for 10 weeks, the students finished one essay, engaged in one peer session, and submitted the final draft after a revision. After finishing the 5th essay, the students were asked to complete the post-survey. Table 1 shows the time line of data collection procedures.

Table 1. Time line of practical data collection procedures

\begin{tabular}{ll}
\hline Time & Activity \\
\hline Week 1-2 & $\begin{array}{l}\text { Pre-survey (5 items) distributed and collected } \\
\text { Two peer review-training workshops }\end{array}$ \\
Week 3-4 & First peer session \\
Essay 1 & First, final drafts, and checklists collected \\
Week 5-6 & Second peer session \\
Essay 2 & First, final drafts, and checklists collected \\
Week 7-8 & Third peer session \\
Essay 3 & First, final drafts, and checklists collected \\
Week 9-10 & Fourth peer session \\
Essay 4 & First, final drafts, and checklists collected \\
Week 11-12 & Fifth peer session \\
Essay 5 & First, final drafts, and checklists collected \\
Week 13 & Post-survey (5 items) distributed and collected \\
\hline
\end{tabular}




\subsubsection{Reliability and Trustworthiness of the Instruments}

Survey. To assess the internal consistency of the survey items, a Cronbach's alpha coefficient was computed for the five items for peer review effectiveness ratings of the pre-/post-survey. The Cronbach's alpha was .91, which indicated high reliability by conventional standards.

Checklist. In order to ensure that the check list is reliable, I used a check list that was used before in the same context. It was designed by a Saudi researcher (Aldossary) in the same university and at the same college in (2016) (see Appendix B).

\subsection{Data Analysis}

Several statistical treatments were applied to analyze the five-item pre-/post-survey. First, a series of independent samples t-tests in SPSS (Version 23.0) was conducted to determine whether students' ratings of peer feedback usefulness were different between the pre- and post-survey. Analyses were conducted separately for each of the five items that assessed participants' perceptions of the overall peer review effectiveness, and an additional analysis assessed Time 1 and Time 2 differences with the five items combined (i.e., composite scores for Time 1 and Time 2 items and their comparison).

To assess participants' acceptance of their classmates' comments and the number of comments incorporated into their final drafts, the students' five essays were carefully examined by implementing quantitative procedures. First, the number of comments on the first draft of each essay was quantified and compared to the number of changes subsequently made in their writings. The percentage of each peer session's comments (i.e., comments made/comments incorporated) was calculated. To determine whether participants incorporated more feedback over time (i.e., between Essay 1 and Essay 5), a repeated-measures ANOVA was conducted with essay number as the within-subjects variable and the proportion of incorporated feedback as the outcome variable.

\section{Results of the Study}

The first question was developed to determine whether students' perceptions of peer feedback usefulness differed between the pre- and post-survey. Six independent sample t-tests (five for each item and one for all five together) were conducted, and Type-1 error rate inflation was controlled via a Bonferroni correction that set alpha at .008 (i.e., .05 divided by 6 tests $=.008$ ). Table 2 shows the five items of the pre-survey (Time 1 ) and post-survey (Time 2), including the mean and $t$ and $p$ values computed from both. As can be seen, all independent sample t-tests returned significant results.

Table 2. Student perceptions of peer review effectiveness at Time 1 and Time 2

\begin{tabular}{|c|c|c|c|c|}
\hline Item & $\begin{array}{l}\text { Time } 1 \text { Mean } \\
(\mathrm{n}=34)\end{array}$ & $\begin{array}{l}\text { Time } 2 \text { Mean } \\
(\mathrm{n}=34)\end{array}$ & $t$ & $p$ \\
\hline 1. I think peer review activities help improve writing. & 2.53 & 3.91 & 5.65 & $<.0001$ \\
\hline 2. It is beneficial to do peer review activities in writing classes. & 2.62 & 4.00 & 5.68 & $<.0001$ \\
\hline 3. I would like to engage in peer review activities in future writing classes. & 2.21 & 3.76 & 5.85 & $<.0001$ \\
\hline 4. I believe teachers should encourage peer review activities in writing classes. & 2.68 & 4.09 & 5.91 & $<.0001$ \\
\hline 5. A good way to improve my writing is to participate in peer review activities. & 2.50 & 3.94 & 5.99 & $<.0001$ \\
\hline Composite of all 5 items & 2.51 & 3.94 & 12.34 & $<.0001$ \\
\hline
\end{tabular}

Most noteworthy, the test comparing the composite of all five items showed the differences in usefulness ratings between pre- $(M=2.51, S D=.83)$ and post-survey $(M=3.94, S D=.91), t=12.34, p=<.0001$. The average mean of all five items in Time 1 was 2.51, indicating a range that lies between disagreement and neutral attitudes toward peer review usefulness; however, perceptions of peer review effectiveness were more positive in Time 2, with an average mean of 3.94, which is near agreement with peer review usefulness.

The second research question assessed participants' acceptance of their classmates' comments and asked whether participants incorporated more feedback over time (i.e., between Essay 1 and Essay 5). It was hypothesized that the proportion of incorporated feedback would increase over time as students became increasingly familiar with the peer review process. Thus, an a-priori planned contrast was used to test for the presence of a linear effect over time (i.e., a steady increase between Essay 1 and 5). Furthermore, to determine whether specific essays differed in the proportion of feedback that was incorporated, post hoc pairwise comparisons were conducted between each essay pair. Due to a large number of comparisons, Type-1 error rate inflation was controlled via a Bonferroni correction. 
As Figure 1 shows, there was a significant linear trend present, $F(1,30)=105.62, p<.001, \eta 2=.78$. The size of this effect $(\eta 2=.78)$ is very large by conventional standards and suggests that almost $80 \%$ of the variance in the amount of incorporated feedback is explained by essay number (i.e., time). Follow-up pairwise comparisons revealed that each pair of essays differed significantly from each other except Essays 2 and 3 as well as Essays 4 and 5 . The descriptive statistics for each essay can be found in Table 3 .

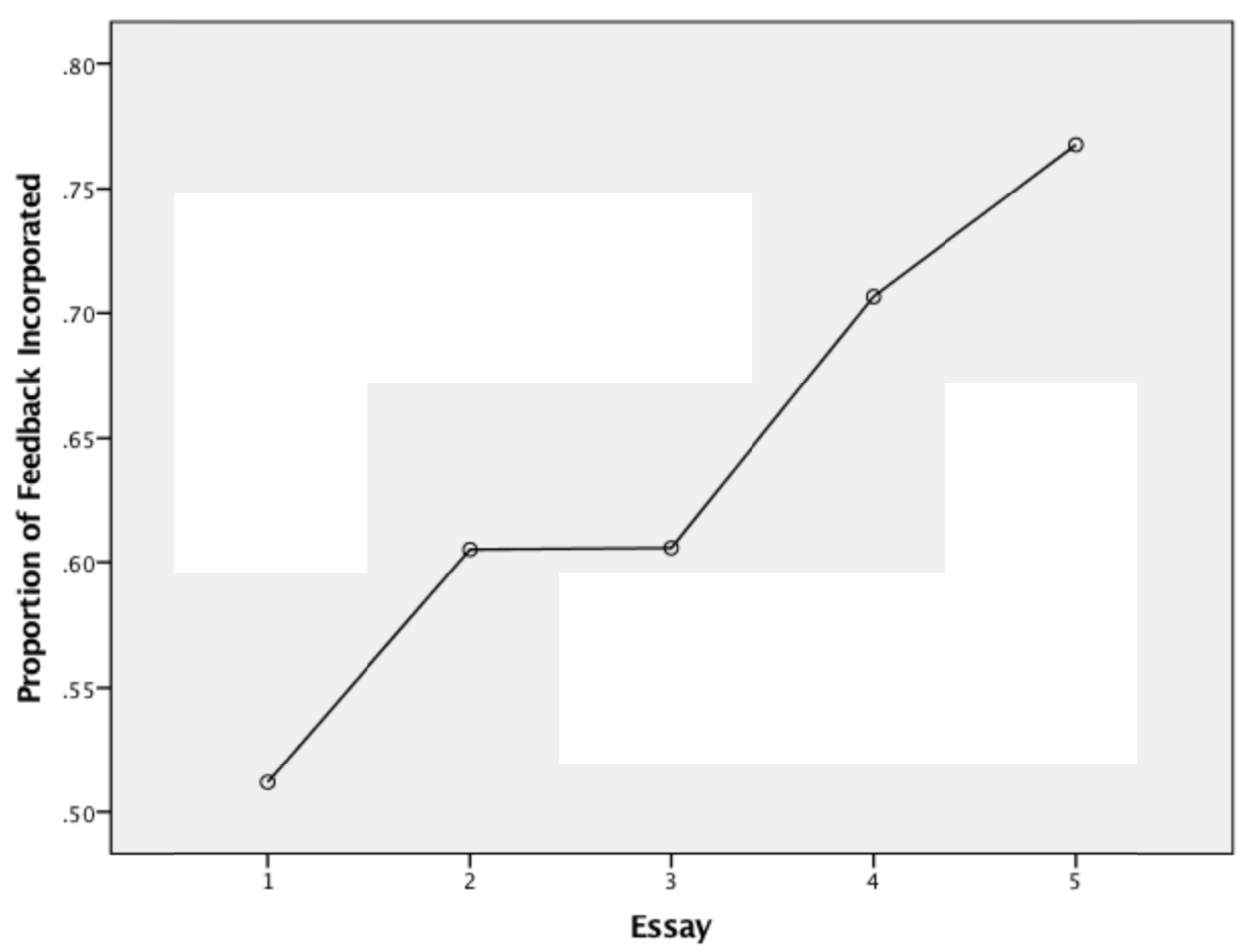

Figure 1. Proportion of feedback incorporated by students for each essay

Table 3. Descriptive statistics for each essay

\begin{tabular}{lllll}
\hline Essay number and topic & $M$ & $S D$ & $95 \%$ CI Low & $95 \%$ CI High \\
\hline 1. Friendship & .51 & 3.94 & .45 & .57 \\
2. Why Choose English Major & .61 & 3.74 & .55 & .66 \\
3. Internet & .61 & 3.71 & .54 & .67 \\
4. Violent Crimes & .71 & 3.82 & .65 & .76 \\
5. Alternative Energy & .77 & 3.80 & .71 & .81 \\
\hline
\end{tabular}

Upon careful examination of these five successive stages of peer sessions, it was evident that the students tended to incorporate more of the comments as they proceeded in writing a new essay. Having multiple chances to use peer feedback on several essays played a crucial role in making students perceive the usefulness of the peer review activity and accept their partners' feedback. Noticeably, the analysis of the students' multiple drafts and checklists demonstrated that not only did the participants accept more comments, but they also performed more local and global revisions and were able to locate more mistakes, particularly local mistakes.

It is important to mention, however, that after the first peer session, many students expressed numerous concerns about the implementation process of peer feedback techniques. These concerns involved issues such as clarification of items on the checklist, providing incorrect comments or ideas, and offering suggestions. The teacher addressed all questions by clarifying the checklist items and reviewing many problematic issues found in the students' first essays. The teacher's intervention might have led the students to integrate more feedback in the second session. As is apparent in Figure 1, there was a large increase in the proportion of comments incorporated into the second essay, an increase that the teacher's direct assistance might have contributed to. Nevertheless, when examining the total number of incorporated comments between the second essay and the final essay (i.e., Peer Session 2 and Peer Session 5), in which there was no direct intervention from a teacher, the 
difference was still highly significant. However, there were many revisions made by the student writers that were not triggered by the peer review. This difference suggested that involvement in multiple peer review sessions over time had a profound impact on the students' willingness to accept the peer comments in this experiment.

\section{Discussion of the Results}

\subsection{Research Question 1}

How do students perceive the effectiveness of peer review on their L2 writing after participating in promoted peer review?

The results obtained from the pre-/post-survey indicate that, following the experiment's conclusion, the participants were more likely to perceive peer review as useful to improve their writing - at first, they had been skeptical about its efficacy and were resistant to participating in such activities, but after engaging in five consecutive peer review sessions, most of them changed their prior views and indicated their willingness to include the activities in EFL writing classes. For example, in the pre-survey, Item 4 ("I believe teachers should encourage peer review activities in writing classes.") got an average rating of 2.68 (between Disagree and Don't Know), which rose to 4.09 (Agree) in the post-survey. Based on participants' responses to the surveys, it can be concluded that the value of peer review would be better recognized if students repeatedly engaged in it and observed its potential benefits.

These findings are consistent with several studies conducted in ESL/EFL contexts (Harutyunyan \& Poveda, 2018; Hojeij \& Baroudi, 2018; Park, 2018). Those studies explained that ESL/EFL students appreciate peer review and believe that engaging in its sessions helps improve their writing. More specifically, Park (2018) revealed that the majority of students appreciated peer feedback because they could learn new perspectives and expressions. Students also felt less obliged to accept all of their peers' comments, compared to teachers' feedback, leading them to critically evaluate their usefulness.

This study confirms the usefulness of training or guidance in changing students' negative perceptions of peer review that was revealed by some previous studies (Bui \& Kong, 2019; Cahyono \& Amrina, 2016; Hojeij \& Baroudi, 2018). Yet this study combined training, guidance, and multiplicity of peer sessions to do the peer review process.

However, this study contradicts many previous studies. Those studies found teacher feedback to be much more beneficial, as students were more likely to use the comments of their teacher than peers when revising their papers, and peer review was seen as counterproductive for students who come from culturally non-Western backgrounds, as they are used to admiring and respecting ranked culture rather than a group consensus among peers (Domysheva \& Kopylova, 2019; Fithriani, 2018; Ruegg, 2018; Suryani et al., 2019).

\subsection{Research Question 2}

To what extent do students accept and incorporate their peers' feedback in L2 writing after participating in promoted peer review?

The in-depth analysis of participants' first and second written drafts and the checklists for the five essays were intended mainly to observe the number of incorporated comments in each essay and assess whether participants incorporated more feedback over time (i.e., between Essay 1 and Essay 5). The amount of incorporated feedback substantially increased over time as students became gradually more familiar with the peer review process and recognized the value of peer comments in improving their writing. The more students engaged in peer sessions, the greater the proportion of comments that were incorporated into the second drafts. This finding is similar to some extent with Bui and Kong (2019). Both studies showed that the level of engagement is increased, and it is important for the development of students' writing; however, they are slightly different. For example, the present study showed that students' engagement is increased as a result of a repetition of the peer review process, whereas Bui and Kong showed that metacognitive training is the reason for the engagement increase.

In the first essay, participants were extremely resistant to using their partners' feedback, as most of the comments were ignored. Furthermore, the analysis revealed that the feedback givers did not locate all problematic issues in the first two peer sessions. Numerous mistakes were overlooked, particularly in the first essay. Nevertheless, as the students engaged in more consecutive peer sessions every 2 weeks, they not only produced more effective comments but also incorporated more of those comments (Appendix C shows examples of comments and their incorporation into the second drafts).

A factor important to making the second peer session more effective was the teacher's approach to peer review. For example, the students encountered difficulties in the first peer session; they were reluctant to give or discuss 
comments and were doubtful about the usefulness of comments received from other classmates. The students needed more clarifications about several peer review techniques and checklist items, and they explained their concerns about their ability to provide correct feedback. However, discussing these issues in the second peer session with the teacher and receiving his encouragement to exchange feedback created an environment in which the students were more likely to trust their peers and share their opinions. This result is similar to Cahyono and Amrina's (2016) study result in that the two studies emphasize the role of the teacher's guidance in facilitating the peer review process.

Nevertheless, the most noticeable result of the student draft analysis was that the participants became more receptive to their partners' comments. Being more responsive to comments indicated that the students valued those comments and identified the peer review activities with enhancing writing skills. This finding related to Research Question 2 was in line with the results mentioned above, obtained from the pre- and post-surveys, reinforcing the reported positive attitudes toward peer review. The increase in incorporated feedback agreed, to some degree, with Pham et al. (2020), who compared the amount of incorporated feedback before and after peer training and found EFL students incorporated a significantly higher quantity of their partners' comments after peer response training. However, in the present study, the amount of incorporated feedback increased over time as students became increasingly familiar with the peer review process and observed its usefulness. This indicates peer review training would not be sufficient for students to entirely comprehend the value of peer review. ESL/EFL students must have ample opportunity to practice peer review repeatedly to improve as reviewers and, therefore, help each other to be better writers.

\subsection{Limitations of the Study}

This study had several limitations that reduced the ability to generalize its findings. First, this study was conducted in only one Saudi university. Thus, the findings cannot be generalized for different EFL contexts, either in Saudi Arabia or in different countries. The cultural and social background of the students in this study restricted the findings to the EFL Saudi context. Moreover, because of the diversity of the Saudi regions as well as English programs taught in several universities within the Saudi context, the findings cannot be generalized to all Saudi students.

Second, due to religious and social restrictions, this study was limited to male students. Female students were not involved, as they are taught in separate colleges. It would thus be interesting to explore the perspectives of different genders regarding the issues discussed in this study.

Third, the scope of the study was limited to student perceptions of the efficacy of peer review using certain techniques over a specific period. Moreover, the participants were EFL students with a specific language proficiency level (upper-intermediate), making it impossible to apply the conclusions of this study to other students with different English language levels.

Finally, there was a limitation regarding data collection and analysis of the pre- and post-surveys. Due to the inability to collect participant names and link individuals' pre-survey and post-survey scores, a dependent samples t-test could not be conducted. It would be more helpful to gather each student's scores and link them to students' demographic information as well as their written essays to reach a deeper interpretation of the data.

\section{Conclusion}

This part concludes the paper with a summary of its key findings, followed by the pedagogical implications for English teachers and learners, as well as suggestions for future research.

\subsection{Summary of the Key Findings}

The analysis of the data revealed a significant relationship between having a positive attitude about peer review and participating repeatedly in different peer sessions over time. In addition, findings presented further support to studies in the literature claiming that frequent practice with peer review activities has been shown to positively affect EFL students' acceptance and incorporation of peer comments and as a result to improve their writing. Acceptance and incorporation increased over time as the students became more familiar with the peer review process. Moreover, using a guide, in the form of a checklist, is of great value that makes peer review easily and smoothly directed, and hence it produces the desired outcomes on the part of the learners.

\subsection{Pedagogical Implications}

Several implications could be identified for both EFL writing teachers and learners.

EFL writing teachers. EFL teachers should train and coach their students in peer review by providing the appropriate preparation that suits the learners' abilities and environment and fulfills their needs. Learners benefit 
from visual guidelines and rubrics to help review each other's writings. It is also necessary to assign sufficient time for peer sessions, as reviewing writing requires considerable effort when following a series of specific tasks. Learners should also be provided with opportunities to discuss their written comments. Ultimately, effective teachers can change EFL students' negative perceptions about peer review and make peer review an essential component that plays an immensely important role in the ongoing writing process.

EFL Saudi learners. Learners would not sufficiently benefit from peer review activities unless they realize that they, as students, are an integral part of the learning process and could contribute to improving their writing and that of others. Teachers are not the only sources of knowledge, and students can learn from each other and be independent learners. Moreover, when students are not given sufficient time in class for peer review, they should seek help from each other outside the classroom and share opinions and feedback on their writings.

\subsection{Suggestions for Future Research}

Although the study findings reveal that EFL students benefited greatly from peer review, more research should be conducted to gain a better understanding of this area of inquiry. Also, other research avenues could be suggested to conduct a similar study but within a different context, or on students of a different gender or linguistic level, to obtain a broader picture of the efficacy of peer review.

\section{Acknowledgments}

The author expresses his appreciation to the Deanship of Scientific Research at King Saud University, Saudi Arabia, and the Research Center at the College of Languages \& Translation for offering support for the current study.

\section{References}

Aldossary, M. (2016). The impact of peer feedback on L2 writing of the givers and the receivers: A longitudinal, mixed-method study in Saudi Arabia. Unpublished doctoral dissertation. The University of Melbourne, Australia.

Austria, M. A. B. (2017). Peer response as an effective writing strategy. International Journal of Progressive Education, 13(2), 95-104.

Azizullah, M., \& Eslami, Z. R. (2015). ZPD-activated languaging and collaborative L2 writing. Educational Psychology, 35(1), 5-25. https://doi.org/10.1080/01443410.2013.814198

Baker, K. (2016). Peer review as a strategy for improving students' writing process. Active Learning in Higher Education, 1-14. https://doi.org/10.1177/1469787416654794

Brusa, M., \& Harutyunyan, L. (2019). Peer review: A tool to enhance the quality of academic written productions. English Language Teaching, 12(5), 30. https://doi.org/10.5539/elt.v12n5p30

Bui, G., \& Kong, A. (2019). Metacognitive instruction for peer review interaction in L2 writing. Journal of Writing Research, 11(2), 357-392. https://doi.org/10.17239/jowr-2019.11.02.05

Cahyono, B. Y., \& Amrina, R. (2016). Peer feedback, self-correction, and writing proficiency of Indonesian EFL students. Arab World English Journal, 7(1), 178-193. https://doi.org/10.24093/awej/vol7no1.12

Domysheva, S. A., \& Kopylova, N. V. (2019). Peer review in EFL writing classrooms at Russian universities: Cultural factors. Vestnik of Samara University. History, Pedagogics, Philology, 3(25), 139-147. https://doi.org/10.18287/2542-0445-2019-25-3-139-147.

Fithriani, R. (2018). Cultural influences on students' perceptions of written feedback in L2 writing. Journal of Foreign Language Teaching \& Learning, 1(3), 1-13. https://doi.org/10.18196/ftl.3124

Harutyunyan, L., \& Poveda, M. F. (2018). Students' perception of peer review in an EFL classroom. English Language Teaching, 11(4), 138-151. https://doi.org/10.5539/elt.v11n4p138

Hojeij, Z., \& Baroudi, S. (2018). Student perceptions on peer feedback training using a blended method: A UAE case. Issues in Educational Research, 3(28), 655-678.

Homayounzadeh, M., Mehrpour, S., \& Saadat, M. (2016). Peer corrective feedback on L2 writing: Does it help improve written accuracy and L2 explicit knowledge over time? The Journal of Language Teaching and Learning, 6(2), 28-45.

Khalil, E. (2018). The efficacy of peer feedback in Turkish EFL students' writing performance. Journal of Literature and Art Studies, 8(6), 920-931. https://doi.org/10.17265/2159-5836/2018.06.011

Kim, S. (2015). Preparing English learners for effective peer review in the writers' workshop. The Reading 
Teacher, 68(8), 599-603. https://doi.org/10.1002/trtr.1358

Kong, A., \& Bui, G. (2019). Reader stances and writer responses in L2 peer review: A study of L2 writing literacy among Hong Kong secondary school students. The Asian EFL Journal, 21(3), 139-186.

Kuyyogsuy, S. (2019). Patterns of interaction on peer feedback: Pair dynamics in developing students' writing skills. International Journal of Higher Education, 3(8), 191-205. https://doi.org/10.5430/ijhe.v8n3p191

Lei, Z. (2017). Salience of student written feedback by peer-revision in EFL writing class. English Language Teaching, 10(12), 151-157. https://doi.org/10.5539/elt.v10n12p151

Leijen, D. A. (2017). A novel approach to examine the impact of web-based peer review on the revisions of L2 writers. Computers and Composition, 43, 35-54. https://doi.org/10.1016/j.compcom.2016.11.005

Memari Hanjani, A. (2019). Collective peer scaffolding, self-revision, and writing progress of novice EFL learners. International Journal of English Studies, 19(1), 41-57. https://doi.org/10.6018/ijes.331771

Memari Hanjani, A., \& Li, L. (2015). Peer collaboration in L2 writing: An Iranian experience. In C. Kennedy (Ed.), English language teaching in the Islamic Republic of Iran: Innovations, trends, and challenges (pp. 93-110). British Council.

Min, H. T. (2016). Effect of teacher modeling and feedback on EFL students' peer review skills in peer review training. Journal of Second Language Writing, 31, 43-57. https://doi.org/10.1016/j.jslw.2016.01.004

Naser, R., \& Behzad, G. (2017). Peer scaffolding behaviors emerging in revising a written task: A microgenetic analysis. Iranian Journal of Language Teaching Research, 5(2), 75-90.

Nguyen, H. T. (2016). Peer feedback practice in EFL tertiary writing classes. English Language Teaching, 9(6), 76-91. https://doi.org/10.5539/elt.v9n6p76

Nguyen, T. T. L. (2019). Implementing peer-feedback in paragraph-writing classes at a Thai university. In S. M. Anwaruddin (Ed.), Knowledge mobilization in TESOL: Connecting research and practice (1st ed., pp. 30-42). Brill. https://doi.org/10.1163/9789004392472_003

Park, J. (2018). Effectiveness of teacher and peer feedback: Through the lens of Korean tertiary writing classroom. The Journal of Asia TEFL, 2(15), 429-444. https://doi.org/10.18823/asiatefl.2018.15.2.11.429

Pham, V. P. H., Huyen, H. L., \& Nguyen, M. T. (2020). The incorporation of quality peer feedback into writing revision. The Asian Journal of Applied Linguistics, 1(7), 45-59.

Ruegg, R. (2018). The effect of peer and teacher feedback on changes in EFL students' writing self-efficacy. The Language Learning Journal, 46(2), 87-102. https://doi.org/10.1080/09571736.2014.958190

Saeed, M. A., Ghazali, K., \& Aljaberi, M. A. (2018). A review of previous studies on ESL/EFL learners' interactional feedback exchanges in face-to-face and computer-assisted peer review of writing. International Journal of Educational Technology in Higher Education, 6(15), 1-25. https://doi.org/10.1186/s41239-017-0084-8

Song, W., \& Usaha, S. (2009). How EFL university students use electronic peer response into revisions. Suranaree Journal of Science and Technology, 16(3), 263-275.

Suryani, R. W., Rozimela, Y., \& Anwar, D. (2019). Exploring the effect of peer feedback and the students' perceptions of the feedback on students' writing skills. International Journal of Secondary Education, 4(7), 116-121. https://doi.org/10.11648/j.ijsedu.20190704.14

Yastibas, G., \& Yastibas, A. E. (2015). The effect of peer feedback on writing anxiety in Turkish EFL (English as a foreign language) students. Procedia - Social and Behavioral Sciences, 199, 530-538. https://doi.org/10.1016/j.sbspro.2015.07.543

Yu, S., \& Lee, I. (2016). Peer feedback in second language writing (2005-2014). Language Teaching, 49(4), 461-493. https://doi.org/10.1017/S0261444816000161

Zhu, Q., \& Carless, D. (2018). Dialogue within peer feedback processes: Clarification and negotiation of meaning. Higher Education Research \& Development, 37(4), 883-897. https://doi.org/10.1080/07294360.2018.1446417 


\section{Appendix A}

\section{5-Item Pre-/Post-Survey Questionnaire on Students' Perceptions of Peer Review Usefulness}

Name (Optional) Date:

This questionnaire is intended to understand your perceptions of the usefulness of peer review for improving your writing. Several statements are provided. Please carefully read them and honestly indicate the extent to which you agree or disagree with each statement. Please circle one of the numbers from 1 to 5 that best describes your opinion.

The scale: 1 = Strongly Disagree, 2 = Disagree, $3=$ Neutral, $4=$ Agree, $5=$ Strongly Agree.

Thank you again for your time and sincere responses!

\begin{tabular}{|c|c|c|c|c|c|}
\hline Statement & SD & D & $\mathbf{N}$ & A & SA \\
\hline 1. I think peer review activities help improve writing. & 1 & 2 & 3 & 4 & 5 \\
\hline 2. It is beneficial to do peer review activities in writing classes. & 1 & 2 & 3 & 4 & 5 \\
\hline 3. I would like to engage in peer review activities in future writing classes. & 1 & 2 & 3 & 4 & 5 \\
\hline 4. I believe teachers should encourage peer review activities in writing classes. & 1 & 2 & 3 & 4 & 5 \\
\hline 5. A good way to improve my writing is to participate in peer review activities. & 1 & 2 & 3 & 4 & 5 \\
\hline
\end{tabular}

\section{Appendix B}

\section{Peer Review Checklist}

Student.................Session.....................

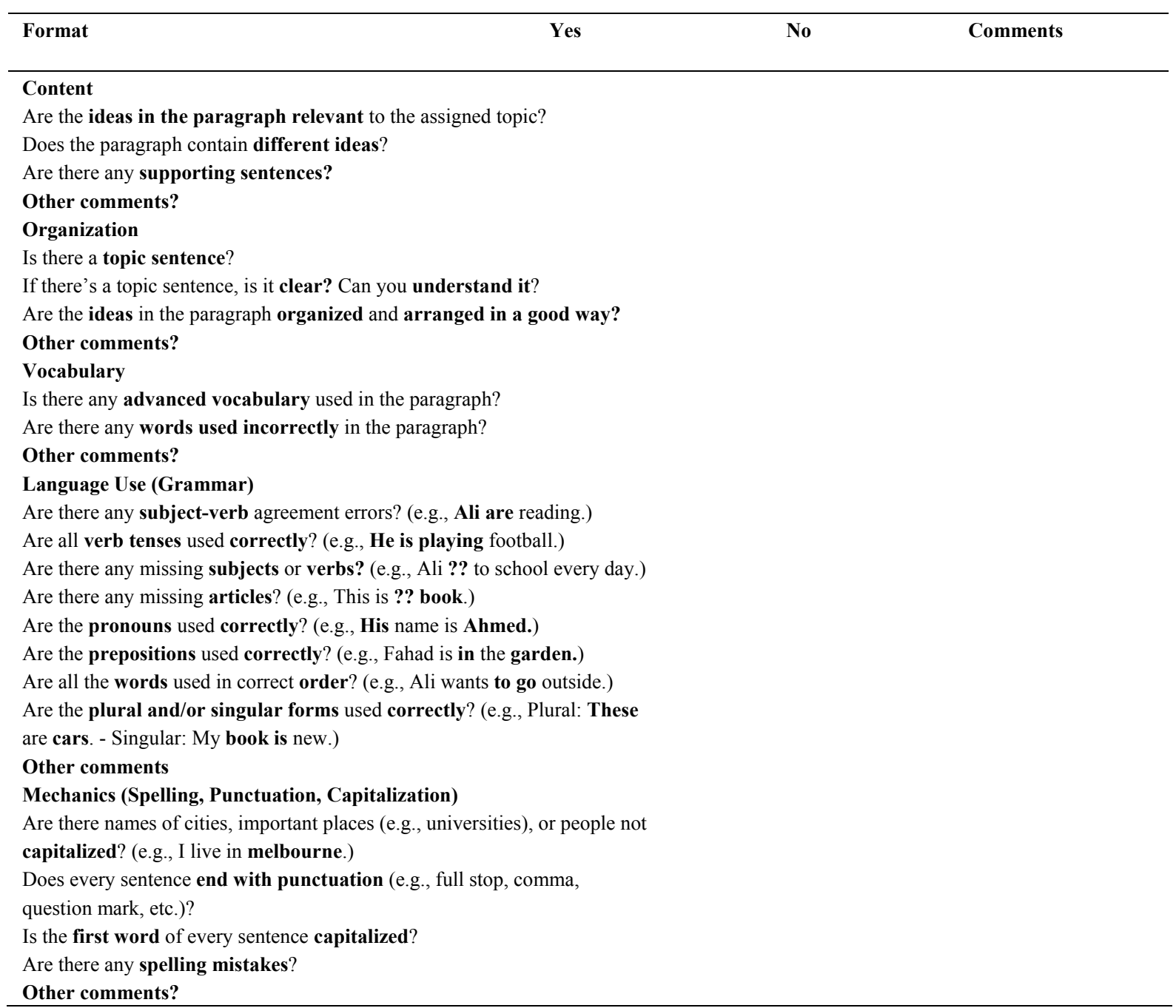




\section{Appendix C}

\section{Examples of Comments and Their Incorporation into Second Drafts}

\begin{tabular}{|c|c|}
\hline Type & Example (changes in boldface) \\
\hline Content & $\begin{array}{l}\text { First draft: My best friend is someone who is special to me. I have a friend and his name is... } \\
\text { Comment: There seems to be a content problem. } \\
\text { The ideas in the paragraph are not relevant to the assigned topic (the assigned topic is friendship). } \\
\text { Second draft: Friendship is very important for our lives. . }\end{array}$ \\
\hline Organization & $\begin{array}{l}\text { First draft: People study English because it is a very important language. } \\
\text { Comment: The topic sentence is not clear, I can not understand it. It is not a good topic sentence. } \\
\text { Second draft: English has become a very important language for several reasons. }\end{array}$ \\
\hline Vocabulary & $\begin{array}{l}\text { First draft: If you want to improve your speaking, it is a good idea to speak by English. } \\
\text { Comment: The use of the word by is not correct. } \\
\text { Second draft: If you want to improve your speaking, it is a good idea to speak in English. }\end{array}$ \\
\hline Language Use (Grammar) & $\begin{array}{l}\text { First draft: The internet change the way we communicate. } \\
\text { Comment: There is no subject-verb agreement. } \\
\text { Second draft: The internet changes the way we communicate. }\end{array}$ \\
\hline $\begin{array}{l}\text { Mechanics (Spelling, } \\
\text { Punctuation, } \\
\text { Capitalization) }\end{array}$ & $\begin{array}{l}\text { First draft: Soler energy becomes popular nowadays. } \\
\text { Comment: There is a spelling mistake in the boldfaced word. } \\
\text { Second draft: Solar energy becomes popular nowadays. First draft: What are the main reasons of violent } \\
\text { crimes. } \\
\text { Comment: A question mark is missing. } \\
\text { Second draft: What are the main reasons of violent crimes? } \\
\text { First draft: violent crimes are the results of watching action films. } \\
\text { Comment: The first letter of this sentence is not capitalized. } \\
\text { Second draft: Violent crimes are the results of watching action films. }\end{array}$ \\
\hline
\end{tabular}

\section{Copyrights}

Copyright for this article is retained by the author, with first publication rights granted to the journal.

This is an open-access article distributed under the terms and conditions of the Creative Commons Attribution license (http://creativecommons.org/licenses/by/4.0/). 